\title{
CIDADANIA E RESPONSABILIDADE SOCIOAMBIENTAL
}

CITIZENSHIP AND ENVIRONMENTAL RESPONSIBILITY

CIUDADANÍA Y RESPONSABILIDAD SOCIOAMBIENTAL

Reis Friede ${ }^{1}$

1 Mestre e Doutor em Direito pela UFRJ, Desembargador Federal e ex-Membro do Ministério Público. Professor do Programa de Mestrado em Desenvolvimento Local da UNISUAM (PPGDL - UNISUAM) e da Universidade Federal Rural do Rio de Janeiro, UFRRJ, Rio de Janeiro, Brasil. E-mail: reisfriede@hotmail.com 
Resumo: O presente estudo examina brevemente o conceito de cidadania e sua evolução histórica. Verifica que, no momento atual, é necessário incorporar neste conceito (e na ação do cidadão) o papel primordial de preservação do meio ambiente. Em seguida, discute a relação antropomórfica do homem em relação à natureza e, por fim, aborda a função socioambiental da propriedade, que consiste em uma atividade exercida não apenas no interesse de seu proprietário, mas, principalmente, no interesse da sociedade.

Palavras-chave: Cidadania. Meio Ambiente. Responsabilidade Socioambiental.

Abstract: The current article examines, briefly, the concept behind the term "citizenship" and its historical evolution. It verifies that, nowadays, it is necessary to include in this concept (and in the actions of the citizens) the primordial role of preserving the environment. Continuing, it debates the anthropomorphic relationship between man and nature. To finish off, it discourses about the social function of properties, which consists of activities not only in the behalf of their owners, but, especially, in the interest of society as a whole.

Keywords: Citizenship. Environment. Social and Environmental Responsibility.

Resumen: El presente estudio examina brevemente el concepto de ciudadanía y su evolución histórica. Verifica que, en el momento actual, es necesario incorporar a este concepto (y a la acción del ciudadano) el papel primordial de preservación del medio ambiente. A continuación, discute la relación antropomórfica del hombre en relación a la naturaleza y, por último, aborda la función socioambiental de la propiedad, que consiste en una actividad ejercida no solo en interés de su propietario, sino principalmente en interés de la sociedad.

Palabras clave: Ciudadanía. Medio Ambiente. Responsabilidad Socioambiental. 


\section{INTRODUÇÃO}

\section{7 palavra cidadania vem do latim civitas, que quer dizer cidade. Na Roma clássica, indicava a situação política de uma pessoa e os direitos - que ela tinha ou podia exercer. Tanto em Roma como na Grécia} Clássica, significava a possibilidade dos cidadãos participarem da vida pública, de interferirem na vida da cidade (civitas em latim e polis em grego). Em ambos os casos, os escravos, que obviamente não possuíam o estatuto de cidadãos (até porque moravam fora de seus muros), estavam excluídos da participação e das benesses proporcionadas pela cidadania.

Vê-se que, desde Roma, a cidadania esteve ligada a privilégios, pois os direitos dos cidadãos eram restritos a determinadas classes e grupos de pessoas. Ao longo da história, porém, seu conceito foi se aprimorando, sendo que na Idade Moderna ocorreu a união dos direitos universais com o conceito de nação, introduzindo os princípios de liberdade e igualdade perante a lei e contra os privilégios. Entretanto, mesmo assim, a cidadania continuava restrita às elites, porque dependia de direitos políticos, vetados para a maioria da população.

No Brasil, o conceito de cidadania vem sendo construído desde o advento da Constituição de 1891 (redigida por Rui Barbosa), sendo que um grande passo em seu desenvolvimento deu-se a partir da promulgação da Constituição de 1988, conhecida como "A Constituição Cidadã".

Segundo Dallari², trata-se de um conceito que expressa um conjunto de direitos que dá à pessoa a possibilidade de participar ativamente da vida e do governo de seu povo. Logo, quem não "tem cidadania está marginalizado ou excluído da vida social e da tomada de decisões, ficando numa posição de inferioridade dentro do grupo social".

Todavia, ainda prevalece entre nós uma inconteste visão reducionista da cidadania, pois se pode afirmar que uma grande parcela dos habitantes das

$\overline{2}$ DALLARI, Dalmo de Abreu. Direitos Humanos e Cidadania. São Paulo: Moderna, 1998. 
cidades (mormente os moradores de áreas favelizadas, onde até pouco tempo o poder público só se fazia presente por meio de intervenções de natureza exclusivamente policiais) ainda não a tem, ou não a exerce, pois na atual sociedade de consumo, ser cidadão significa ter recursos para consumir, conforme diria Nestor Clancline ${ }^{3}$.

O conceito contemporâneo de cidadania reside, sobretudo, na concepção estruturante que preconiza que esta não deve mais se resumir a um conjunto de direitos e deveres políticos e sociais: ela deve se desenvolver alicerçada na capacidade popular de organização, participação e intervenção social, com vistas também a possibilitar que o ambiente (construído) seja visto, planejado e preservado pensando nas gerações futuras.

Por conseguinte, deve compreender um conjunto de deveres não só do cidadão para com o Estado e com a nação derivada, mas também com o próximo e, em especial, com o meio ambiente (com o planeta), uma vez que somos parte de um ecossistema complexo que funciona de maneira integrada.

\section{O HOMEM E A CONCEPÇÃO ANTROPOMÓRFICA}

O homem, até pouco tempo, era visto sobretudo como um elemento superior e extrínseco em relação ao meio ambiente (sujeito apenas de direitos no que pertine a este), precisando refazer o caminho de integração como parte componente que é deste, na qualidade fundamental de sujeito também de deveres para com toda a biosfera. É importante consignar, por oportuno, que biosfera é o conjunto de todos os ecossistemas da Terra, resultado da conjunção de causas astronômicas, geofísicas, geoquímicas e biológicas frequentemente ligadas entre si por relações de interdependência, ao passo que meio ambiente é o conjunto de condições, leis, influências e infraestrutura de ordem física, química e biológica que permite, abriga e rege a vida em todas as suas formas ${ }^{4}$.

3 CANCLINI, Néstor García. Consumidores e cidadãos: conflitos multiculturais da globalização. Rio de Janeiro: Editora UFRJ, 2006.

4 WEBBER, Alexandra Andréa. A Proteção das Reservas de Biosfera no Direito Internacional Ambiental: Aspectos Jurídicos Relevantes a Proteção das Reservas de Biosfera. Disponível em: <revista.esmesc.org.br/re/article/download/28/32>. Acesso em: <8 Mai 2014>. 
A concepção estruturante antropomórfica do homem no centro de tudo requer, portanto, mudança de concepção (de pensar e de sentir), ainda que se apresente com enorme dificuldade de ser rompida, eis que é a visão que perdurou durante praticamente toda a história da espécie humana: o homem - e apenas este - era a razão da existência de tudo à sua volta, o exemplar máximo da perfeição da criação divina, tese esta corroborada fortemente no Mundo Ocidental pela base filosófico-religiosa judaico-cristã. A concepção fundamental e uníssona desta tese repousa, acima de tudo, na ideia de superioridade do gênero humano sobre o meio ambiente e está no livro Gênesis da Bíblia.

Trata-se não somente de uma questão de simplesmente repensar o homem, mas, em termos mais realistas, de reformular o papel do gênero humano na sociedade organizada, criando novos pilares a partir dos quais deve ser construída uma nova concepção político-jurídica de cidadania - com novos paradigmas de direitos e obrigações -, ampliando, consequentemente, a limitada noção de responsabilidade social para incorporar o meio ambiente e sua correspondente responsabilidade, forçando o desenvolvimento de um novo e ampliado conceito de responsabilidade socioambiental. Modernamente já se conceitua cidadão como sendo "o indivíduo que tem direito a ter direitos" 5 . Assim, entende-se que, para se ter direito a ter direitos, é necessário cumprir determinados deveres, obrigações, que seriam a contrapartida na obtenção de benesses proporcionadas pelo Estado-Nação.

O termo meio ambiente é conceituado na lei que instituiu a Política Nacional do Meio Ambiente (Lei $\mathrm{n}^{\circ}$ 6.938/19816), em seu artigo $3^{\circ}$, inciso I, como "o conjunto de condições, leis, influências e interações de ordem física, química e biológica, que permite, abriga e rege a vida em todas as suas formas". Assim, o homem, como habitante da Terra, é uma destas formas de vida que é abrigada e regida pelo meio ambiente, posto que é este conjunto de fatores que possibilita à espécie humana sobreviver neste planeta.

5 D'URSO, Luiz Flávio Borges. A Construção da Cidadania. Disponível em: <http://www. oabsp.org.br/palavra_presidente/2005/88/> Acessado em: <22 Abr 2014>.

6 BRASIL. Lei no $\mathbf{6 . 9 3 8}$, de 31 de agosto de 1981. Dispõe sobre a Política Nacional do Meio Ambiente, seus fins e mecanismos de formulação e aplicação, e dá outras providências. Brasília: Diário Oficial da União de 2 set. 1981. Disponível em: http://www.planalto. gov.br/ccivil_03/leis/L6938.htm. Acesso em: <2 Abr. 2014>. 
Durante muitos séculos, o ser humano utilizou-se da matéria-prima abundante ao seu redor para se desenvolver e evoluir, enriquecer, conceber domínios, etc. Tal uso não conseguiu, porém, diminuir a capacidade de regeneração do meio ambiente, seja pelo número de habitantes do mundo não pesar sobre esta capacidade durante aqueles tempos ${ }^{7}$, seja por ainda não serem utilizados métodos mais agressivos na consecução dos objetivos pretendidos.

\section{O DESENVOLVIMENTO INSUSTENTÁVEL}

Entretanto, tudo mudou nos últimos 250 (duzentos e cinquenta) anos, com o início da chamada Revolução Industrial, que foi um fenômeno de transição para inéditos processos de manufatura no período que se estendeu da segunda metade do século XVIII até quase o fim da segunda metade do século subsequente. Esta transformação incluiu a substituição de métodos de produção artesanais para a produção por máquinas; a fabricação de novos produtos químicos, novos processos de produção de ferro; maior eficiência na utilização da energia hídrica; o uso crescente da energia a vapor; o desenvolvimento das máquinasferramentas; além da substituição da madeira e de outros biocombustíveis pelo carvão. Iniciada na Inglaterra, tal revolução espalhou-se em poucas décadas para o restante da Europa Ocidental e para os Estados Unidos ${ }^{8}$.

Este marco temporal foi o ponto de partida para mudanças sentidas até os dias de hoje ao redor do globo, tais como a mecanização produtiva, o aumento populacional em virtude de melhores condições de vida (não obstante a piora expressiva destas para as classes sociais mais baixas durante suas primeiras décadas), o desenvolvimento tecnológico e social, etc. Ocorre que referida revolução, obviamente como toda mudança, trouxe problemas que apenas nas últimas décadas começaram a ser mais bem percebidos, bem como devidamente debatidos e enfrentados.

7 FRIEDE, Reis. "A Raiz Matricial do Rompimento da Estabilidade Ambiental". São Paulo: Revbea, V. 9, No 1: 37-42, 2014.

8 DANEMBERG, Juliana Morais. Primeira Revolução Industrial: aspectos sociais, econômicos e políticos. Disponível em: www.historia.uff.br/nec/.../Juliana_primeira_revolindusrevis.doc. Acesso em: <9 Maio 2014>. 
Se antes a população mundial não era um fardo para o planeta, seu crescimento geométrico tornou-se uma questão a ser tratada com enorme cuidado ${ }^{9}$. Se a humanidade levou milhares de anos para chegar à marca do bilhão de habitantes, bastou pouco mais de 200 (duzentos) anos para se atingir a marca atual. Entre 1800 e 2010, a população mundial cresceu aproximadamente sete vezes - de 1 para 7 bilhões de habitantes ${ }^{10}$.

Como alimentar os habitantes de toda a Terra sem exaurir suas lavouras e sem causar a extinção de inúmeras espécies de animais? Ademais, como sustentar o aumento qualitativo nas condições de vida da humanidade se muitos recursos utilizados para tanto já estão perto de seu esgotamento, existindo cálculos de que seria necessário aproximadamente um planeta e meio em recursos naturais para mantermos a capacidade de regeneração da Terra?

Segundo dados da Global Footprint Network ${ }^{11}$, a pegada ecológica da humanidade atingiu a marca de 2,7 hectares globais (gha) por pessoa, em 2007, para uma população mundial de 6,7 bilhões de habitantes na mesma data (segundo a ONU). Isto significa que, para sustentar esta população, seriam necessários 18,1 bilhões de gha; entretanto, o planeta Terra possui aproximadamente 13,4 bilhões de hectares globais (gha) de terra e água biologicamente produtivas.

É exatamente nesse contexto analítico que a importância do homem é revelada, particularmente no que diz respeito à sua mandatória inserção no meio ambiente, uma vez que, na qualidade de ser pensante, ele precisa entender que a sociedade de consumo tal como está estruturada não é sustentável. É desta compreensão que surge a ideia de desenvolvimento sustentável. E todas estas questões dizem respeito à educação, ou estão intrinsecamente ligadas a ela, pois é na escola que a "civilização ocidental" aprendeu que o homem é superior e não aprendeu que os recursos naturais da Terra não eram finitos. Na verdade, a escola não ensinou nem o respeito utilitarista ao Planeta.

9 FRIEDE, Reis. "A Hipocrisia Ambiental". Revista da EMERJ, v. 13, no 50, 2010.

10 ALVES, José Eustáquio Diniz. A Terra no limite. Disponível em: http://planetasustentavel.abril.com.br/noticia/ambiente/terra-limite-humanidade-recursos-naturais-planetasituacao-sustentavel-637804.shtml. Acesso em: <25 Abr 2014>.

11 GLOBAL FOOTPRINT NETWORK. Disponível em: < http://www.footprintnetwork.org/ar/index.php/GFN/page/footprint_data_and_results/>. Acesso: 14 de maoi de 2014. 
As normas jurídicas revelam o nível do estágio de consciência de uma dita sociedade. Em se tratando de questões relativas ao meio ambiente, a Constituição da República Federativa do Brasil (CRFB) de 1988, de forma inédita e em perfeita sintonia com o processo de constitucionalização da tutela do meio ambiente, dedicou ao tema um capítulo (Capítulo VI - Do Meio Ambiente, Título VIII Da Ordem Social) inteiramente destinado a assegurar tal proteção, conforme previsão contida no artigo 225, assim transcrito: "Todos têm direito ao meio ambiente ecologicamente equilibrado, bem de uso comum do povo e essencial à sadia qualidade de vida, impondo-se ao Poder Público e à coletividade o dever de defendê-lo e preservá-lo para as presentes e futuras gerações" ${ }^{12}$.De acordo com Horta $^{13}$, em matéria de defesa do meio ambiente, a legislação federal brasileira, toda ela posterior ao clamor recolhido pela Conferência de Estocolmo, percorreu três etapas no período de tratamento autônomo, iniciado em 1975:

A primeira, caracterizada pela política preventiva, exercida por órgãos da administração federal, predominantemente; a segunda coincide com a formulação da Política Nacional do Meio Ambiente, a previsão de sanções e a introdução do princípio da responsabilidade objetiva, independentemente da culpa, para indenização ou reparação do dano causado; e a terceira representada por dupla inovação: a criação da ação civil pública de responsabilidade por danos causados ao meio ambiente, sob a jurisdição do Poder Judiciário, e a atribuição ao Ministério Público da função de patrono dos interesses difusos da coletividade no domínio do meio ambiente ${ }^{14}$. (HORTA, 2002, p. 270).

Toda esta evolução legislativa demonstra como o homem já é visto no Estado Brasileiro como um sujeito não apenas de direitos, mas também de deveres para com o meio ambiente, restando umbilicalmente integrado a este e dele sendo plenamente indissociável.

O parágrafo primeiro do mesmo artigo esmiúça em vários incisos as tarefas do Poder Público para efetivação desse direito, com destaque para: criação de espaços territoriais e seus componentes a serem especialmente protegidos (inciso III); estudo prévio de impacto ambiental para instalação de obra ou atividade

12 BRASIL. Constituição Federal de 1988. Brasília, 1988.

13 HORTA, Raul Machado. Direito Constitucional. Belo Horizonte: Del Rey, 2002.

14 HORTA, Raul Machado. Direito Constitucional. Belo Horizonte: Del Rey, 2002. 
potencialmente causadora de degradação do meio ambiente (inciso IV); promoção da educação ambiental em todos os níveis de ensino e conscientização pública para a preservação do meio ambiente (inciso VI); proteção da fauna e da flora e vedação às práticas que coloquem em risco sua função ecológica e provoquem a extinção de espécies ou submetam animais a crueldade (inciso VII).

O parágrafo segundo versa sobre a obrigação dos que exploram recursos naturais de recuperar o meio ambiente degradado, de acordo com solução técnica exigida pelo órgão público competente; já o parágrafo terceiro trata das sanções penais e administrativas às condutas e às atividades consideradas lesivas ao meio ambiente, independentemente da obrigação de reparar os danos causados.

Da leitura do citado artigo, notadamente de seu caput, percebe-se de forma nítida que o Estado brasileiro já entende o ser humano como parte integrante e indissociável do meio ambiente, concedendo-Ihe o direito de dele usufruir de uma maneira ecologicamente equilibrada, mas também lhe impondo o dever de defendê-lo e preservá-lo para si e para as gerações vindouras.

Essa necessária simbiose entre o direito e o devercom relação ao meio ambiente fazse ainda mais importante se se levar em consideração que a pujança do Brasil sempre decorreu, em grande parte, de sua produção agrícola, cujos cultivos da cana-de-açúcar e do café, bem como a agricultura mecanizada de hoje em dia, proporcionaram e ainda propiciam longos períodos de desenvolvimento econômico.

Sem sombra de dúvidas, o Brasil é um país privilegiado no que diz respeito à posição geográfica no globo, possui a maior área agrícola cultivável em que pese ser apenas o quinto país em área territorial. A fronteira agrícola do país já está perto de atingir sua área territorial máxima sem adentrar as áreas urbanas e as áreas de proteção ambiental ${ }^{15}$. Assim, não se pode, sob a ânsia do desenvolvimento a qualquer custo, prejudicar o meio ambiente para gerar mais riqueza, pois os problemas que serão gerados (desertificação, erosão, falta d'água, poluição, para citar os mais comuns) cairão sobre os habitantes. A saída para conciliar crescimento econômico e sustentabilidade ambiental, por conseguinte, virá do 15 MEDEIROS, Rodrigo; YOUNG, Carlos Eduardo Frickmann. Contribuição das Unidades de

Conservação Brasileiras para a Economia Nacional. Disponível em: http://www.mma. gov.br/estruturas/240/_arquivos/relatorio_final_contribuio_uc_para_a_economia_nacional_reduzido_240.pdf. Acesso em: <22 Maio 2014>. 
necessário desenvolvimento tecnológico, o que não deve ocorrer só pelas mãos da iniciativa privada, mas também deve ser incentivado pelo setor público.

Todavia, setores de alguns países ainda não percebem o homem como uma parte do meio ambiente, insistindo na prática do desenvolvimento econômico a qualquer custo, dentre eles empresários da maior economia da atualidade, os Estados Unidos. Um exemplo recente é a exploração de gás de xisto pelo método de fratura hidráulica, que pode afetar o meio ambiente em decorrência do vazamento de produtos químicos utilizados na extração do gás para lençóis freáticos e pela liberação de gases causadores do efeito estufa para a atmosfera. O gás de xisto é um gás natural encontrado dentro de formações de xisto. Sua exploração ganhou força no início deste século, especialmente nos Estados Unidos, sendo vista como uma forma de energia alternativa ao petróleo, proveniente de áreas distantes como o Oriente Médio ${ }^{16}$.

Para a obtenção do referido gás, devido à profundidade em que se encontra, o método mais utilizado é o conhecido como "fratura hidráulica", em que se injeta líquido misturado com areia ou agentes químicos com o intuito de fragmentar a rocha, para que o gás retido seja liberado. A areia e os agentes químicos utilizados funcionam como preenchedores dos espaços vazios de onde saiu o gás que é liberado para os poços. Entretanto, relatam-se diversos problemas envolvendo tal método, desde possíveis tremores de terra até a liberação de agentes cancerígenos ou poluidores de lençóis freáticos.

As sociedades tradicionalmente poluidoras têm apelado para métodos drásticos na mudança de relação com o meio ambiente, como é o caso da China, que declarou "guerra" à poluição ${ }^{17}$. Uma das principais armas nesta batalha está sendo a imposição da redução do uso do carvão como fonte de energia. O corte no consumo de carvão, a principal fonte de energia no país, deve chegar a 220 milhões de toneladas este ano, um aumento de 3,9\% em relação a 2013.

16 WHAT IS SHALE GAS AND WHY IS IT IMPORTANT? Disponível em: <http://www.eia.gov/ energy_in_brief/article/about_shale_gas.cfm> Acesso: 9 Maio 2014.

17 Guerra à poluição na China será "batalha difícil", diz primeiro-ministro. Agência Brasil, Brasília, 13 Mar 2014. Disponível em: http://agenciabrasil.ebc.com.br/internacional/noticia/ 2014-03/guerra-poluicao-na-china-sera-batalha-dificil-diz-primeiro-ministro. Acesso em: $<28$ Abr 2014>. 
Por conseguinte, a tão almejada formação do novo conceito de cidadão infelizmente não se concretizará enquanto ainda restarem no seio da sociedade global grupos com instinto destrutivo, característicos da humanidade até poucas décadas atrás. Esses grupos interessados somente no lucro imediato, a qualquer custo, deverão ser contidos por leis e dispositivos de pressão pública da população. O cidadão não pode e não deve aceitar o rio poluído sem nada fazer.

\section{A RESPONSABILIDADE SOCIOAMBIENTAL}

Em que pese a responsabilidade social ainda ser um conceito relativamente recente para boa parte da sociedade - posto que surgiu com força apenas na segunda metade do Século XX -, a verdade é que já se convive, na atualidade, com a natural evolução desta, ou seja, a responsabilidade socioambiental, conforme se verifica na redação do artigo 186, sobre a função ambiental da propriedade:

A função social é cumprida quando a propriedade rural atende, simultaneamente, segundo critérios e graus de exigência estabelecidos em lei, aos seguintes requisitos: I - aproveitamento racional e adequado; II - utilização adequada dos recursos naturais disponíveis e preservação do meio ambiente; III - observância das disposições que regulam as relações de trabalho; IV - exploração que favoreça o bem-estar dos proprietários e dos trabalhadores. ${ }^{18}$

Ainda que a responsabilidade social englobe a ideia de que o mundo corporativo, voluntariamente, dará sua parte de contribuição para uma sociedade mais justa e um meio ambiente mais limpo, o certo é que o que a difere de sua evolução é o enfoque dado a seus bens maiores.

Enquanto que no conceito de responsabilidade social a sociedade ocupa o patamar mais elevado como objetivo das ações do voluntariado, a responsabilidade socioambiental tem o meio ambiente como o bem a ser protegido com mais afinco, e com enorme razão, eis que é este, conforme já visto anteriormente, que abriga e rege a vida em todas as suas formas.

Essa nova responsabilidade não deve, porém, ser promovida apenas pelo 18 BORGES, Roxana Cardoso Brasileiro. Função ambiental da propriedade Rural. São Paulo: LTr, 1999. 
empresariado, mas também pelo Poder Público e pelos próprios cidadãos segundo se infere da leitura do caput do artigo 225 da CRFB -, nas mais variadas vertentes, sob pena de não se conseguir uma proteção do meio ambiente plenamente integrada.

Com relação ao Poder Público, um exemplo de promoção da responsabilidade socioambiental é a recente mudança de paradigma na visão referente à proteção da propriedade privada, cuja função a ser exercida não deve mais se resumir apenas à social.

A Constituição de 1988 já faz menção a essa nova ideia em seu artigo 186, pensamento que foi mais bem explorado no Código Civil de 2002 - festejado por

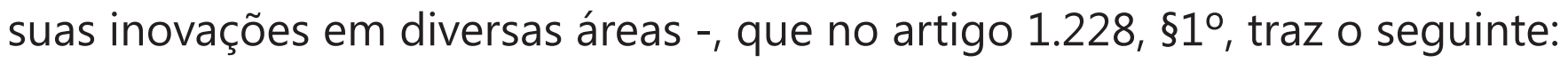

$\S 100$ direito de propriedade deve ser exercido em consonância com as suas finalidades econômicas e sociais e de modo que sejam preservados, de conformidade com o estabelecido em lei especial, a flora, a fauna, as belezas naturais, o equilíbrio ecológico e o patrimônio histórico e artístico, bem como evitada a poluição do ar e das águas. ${ }^{19}$

Fazendo a necessária exegese dos mencionados textos legais, extrai-se que o Poder Público passou a enxergar a função socioambiental da propriedade como algo que consiste em uma atividade exercida no interesse não apenas de seu proprietário, mas, principalmente, no interesse da sociedade. Deste modo, a função ambiental volta-se para a manutenção do equilíbrio ecológico como interesse de todos, beneficiando a sociedade e o próprio cidadão proprietário, sendo uma importante aliada no cumprimento desta função à delimitação das chamadas reservas legais.

Outro exemplo contemporâneo de mudança por parte do Poder Público na forma de abordar a temática ambiental - e que demonstra seu interesse em promover a responsabilidade socioambiental - é a utilização cada vez mais frequente do Princípio do Poluidor-Pagador, que leva à responsabilização de grandes empresas por danos ambientais e ao aumento da criação de unidades de conservação ambiental nos últimos 20 (vinte) anos, que leva em conta que os recursos ambientais são escassos e a produção de bens de consumo gera reflexos, 19 BRASIL. Constituição Federal de 1988. Brasília, 1988. 
resultando em sua degradação e escassez. Além do mais, ao utilizar gratuitamente um recurso ambiental, está se gerando um enriquecimento ilícito, pois como o meio ambiente é um bem que pertence a todos, boa parte da comunidade nem utiliza um determinado recurso, ou, se utiliza, o faz em menor escala.

As unidades de conservação cumprem uma série de funções cujos benefícios são usufruídos por grande parte da população brasileira - inclusive por setores econômicos em contínuo crescimento, sem que se deem conta disto. Alguns exemplos: parte expressiva da qualidade e da quantidade da água que compõe os reservatórios de usinas hidrelétricas, provendo energia a cidades e indústrias, é assegurada por unidades de conservação. O turismo que dinamiza a economia de muitos dos municípios do país só é possível pela proteção de paisagens proporcionada pela presença de unidades de conservação.

O desenvolvimento de fármacos e cosméticos consumidos cotidianamente, em muitos casos, utiliza espécies protegidas por unidades de conservação. Ao mesmo tempo, as unidades de conservação contribuem de forma efetiva para enfrentar um dos grandes desafios contemporâneos, a mudança climática. Ao mitigar a emissão de gás carbônico e de outros gases de efeito estufa decorrente da degradação de ecossistemas naturais, as unidades de conservação ajudam a impedir o aumento da concentração destes gases na atmosfera terrestre.

Estes exemplos permitem constatar que estes espaços protegidos desempenham papel crucial na proteção de recursos estratégicos para o desenvolvimento do país, um aspecto pouco percebido pela maior parte da sociedade, incluindo tomadores de decisão, e que, ademais, possibilita enfrentar o aquecimento global.

Quanto ao papel dos cidadãos, pequenas ações condizentes com o conceito de responsabilidade socioambiental já teriam o condão de auxiliar na construção de uma nova concepção político-jurídica de cidadania, tais como a economia no uso da água e da energia elétrica, a maior utilização do transporte público em detrimento do veículo particular, etc., além da participação política no sentido de apoiar ações em prol do ambiente.

Vê-se, portanto, que é crucial que não apenas o mundo corporativo promova 
a responsabilidade socioambiental, pois só com a contribuição dos três diferentes grupos citados é que se estará protegendo a contento o meio ambiente.

O momento atual encerra um importante capítulo de nossa história jurídicohermenêutica no que concerne, em especial, à questão da cidadania. Tal momento não somente permite, mas, verdadeiramente, obriga-nos à reflexão que conduzirá ao estabelecimento de um novo e mais amplo conceito de responsabilidade individual e coletiva, logo, de cidadania.

Nesse sentido, devem-se questionar paradigmas anteriores, que percebiam os problemas humanos de forma simplista e fragmentada, fundados no método cartesiano de pensar. Esta visão, conforme Morin ${ }^{20}$, inevitavelmente teria conduzido à atual crise ambiental, que exige repensar os paradigmas educacionais disciplinares para que se possa formar uma nova (e ampliada) concepção de cidadania, incluindo a responsabilidade socioambiental.

\section{CONSIDERAÇÕES FINAIS}

Após a reflexão trazida por este estudo, constata-se que somente com a necessária criação de uma nova concepção de "cidadania" é que a humanidade conseguirá ultrapassar o atual momento em que se vive sem maiores prejuízos ou sofrimentos. Não há dúvidas de que se está presenciando o fim da vida em sociedade tal como se conhece, mas cabe somente ao ser humano fazer esta transição de modo de vida de uma maneira que este fim seja um novo começo - mais racional e harmonizador -, e não um ponto final na existência de uma humanidade saudável neste planeta.

Para tanto, a formação de um novo conceito de cidadão faz-se mandatória, pois só assim o homem passará a se ver como parte integrante e indissociável do meio ambiente, pautando suas ações com base na responsabilidade socioambiental - responsabilidade esta que deverá ser o norte de atuação também para o mundo corporativo e o Poder Público - e tendo um papel primordial na preservação do meio ambiente.

20 MORIN, Edgar. Os Sete Saberes Necessários a Educação do Futuro. 2. ed. Rio de Janeiro: Cortez, 2011 
Como diria Antonio Houaiss ${ }^{21}$, a falta de "cidadania ambiental" nos diversos países (os desenvolvidos já esgotaram as suas matérias-primas e os subdesenvolvidos estão em rota de esgotamento) só contribuirá, cada vez mais, para o esgotamento dos recursos naturais necessários à manutenção de nossa própria existência no planeta. Não é por outra razão, portanto, que deve ser reconhecida aos cidadãos a efetiva existência de novos deveres condizentes com a realidade pautada pelo reconhecimento do ser humano como parte integrante e indissociável do próprio meio ambiente, e não mais como elemento diverso que apenas utiliza, em seu benefício, os recursos disponibilizados pela biosfera. Muitos, aliás, contaminam os bens ambientais que são de todos (como o ar e a água) em benefício de seu próprio enriquecimento.

\section{REFERÊNCIAS}

ALVES, José Eustáquio Diniz. A Terra no limite. Disponível em: < http://planetasustentavel. abril.com.br/noticia/ambiente/terra-limite-humanidade-recursos-naturais-planeta-situacaosustentavel-637804.shtml> Acesso em: <25 Abr. 2014>.

BORGES, Roxana Cardoso Brasileiro. Função ambiental da propriedade Rural. São Paulo: LTr, 1999.

BRASIL. Constituição Federal de 1988. Brasília, 1988.

BRASIL. Lei $\mathbf{n}^{\circ} \mathbf{6 . 9 3 8}$, de 31 de agosto de 1981. Dispõe sobre a Política Nacional do Meio Ambiente, seus fins e mecanismos de formulação e aplicação, e dá outras providências. Brasília: Diário Oficial da União de 2 set. 1981. Disponível em: http://www.planalto.gov.br/ ccivil_03/leis/L6938.htm. Acesso em: <2 Abr. 2014>.

CANCLINI, Néstor García. Consumidores e cidadãos: conflitos multiculturais da globalização. Rio de Janeiro: Editora UFRJ, 2006.

DALLARI, Dalmo de Abreu. Direitos Humanos e Cidadania. São Paulo: Moderna, 1998.

DANEMBERG, Juliana Morais. Primeira Revolução Industrial: aspectos sociais, econômicos e políticos. Disponível em: www.historia.uff.br/nec/.../Juliana_primeira_revolindusrevis.doc. Acesso em: <9 Maio 2014>.

21 HOUAISS, Antonio. Dicionário eletrônico Houaiss da língua portuguesa. Disponível em: http://houaiss.uol.com.br/. Acesso: 03 de maio de 2014. 
D'URSO, Luiz Flávio Borges. A Construção da Cidadania. Disponível em: http://www.oabsp. org.br/palavra_presidente/2005/88/. Acessa em: <22 Abr. 2014>.

FRIEDE, Reis. A Hipocrisia Ambiental. Revista da EMERJ, v. 13, nº 50, 2010.

FRIEDE, Reis. A Raiz Matricial do Rompimento da Estabilidade Ambiental. Revbea, São Paulo, V. 9, No 1: 37-42, 2014.

HORTA, Raul Machado. Direito Constitucional. Belo Horizonte: Del Rey, 2002.

GLOBAL FOOTPRINT NETWORK. Disponível em: http://www.footprintnetwork. org/ar/index. php/GFN/page/footprint_data_and_results/>. Acesso: 14 de maio de 2014.

HOUAISS, Antonio. Dicionário eletrônico Houaiss da língua portuguesa. Disponível em <http://houaiss.uol.com.br/>. Acesso: 03 de maio de 2014.

MEDEIROS, Rodrigo. YOUNG, Carlos Eduardo Frickmann. Contribuição das Unidades de Conservação Brasileiras para a Economia Nacional. Disponível em: http://www.mma. gov.br/estruturas/240/_arquivos/relatorio_final_ contribuio_uc_para_a_economia_nacional_ reduzido_240.pdf> Acesso em: <22 Maio 2014>.

MORIN, Edgar. Os Sete Saberes Necessários a Educação do Futuro. 2. ed. Rio de Janeiro: Cortez, 2011.

WEBBER, Alexandra Andréa. A Proteção das Reservas de Biosfera no Direito Internacional Ambiental: Aspectos Jurídicos Relevantes a Proteção das Reservas de Biosfera. Disponível em: <revista.esmesc.org.br/re/article/ download/28/32>. Acesso em: <8 Maio 2014>.

Guerra à poluição na China será "batalha difícil", diz primeiro-ministro. Agência Brasil, Brasília, 13 Mar 2014. Disponível em: < http://agenciabrasil.ebc.com.br/internacional/noticia/2014-03/guerrapoluicao-na-china-sera-batalha-dificil-diz-primeiro-ministro $>$. Acesso em: <28 Abr. 2014>.

0 que é a Responsabilidade Social Empresarial? Disponível em: http://www.adam-europe. eu/prj/5241/prj/Formacao\%20em\%20RSE_PT.pdf. Acesso em: <9 Maio 2014>.

Princípios do Direito Ambiental. Disponível em: http://www.jurisambiente.com.br/ambiente/ principios.shtm. Acesso em: <22 Maio 2014>.

What is shale gas and why is it important? Disponivel em: http://www.eia.gov/energy_in_ brief/article/about_shale_gas.cfm. Acesso em: <9 Maio 2014>.

Recebido em: set/2014

Aprovado em: abr/2015 